\title{
COMPARATIVE STUDY ON THE DYEABILITY OF COTTON, SILK AND POLYESTER FABRICS BY CONVENTIONAL AND ELECTROCHEMICAL METHODS
}

\author{
K. Kalapriya ${ }^{1, *}$, H. Gurumallesh Prabu ${ }^{2}$ and S. Nithya ${ }^{3}$ \\ ${ }^{1}$ Department of Chemistry, Kumaraguru College of Technology, \\ Coimbatore-641049,TN, India \\ ${ }^{2}$ Department of Industrial Chemistry, Alagappa University, Karaikudi-630003, TN, India \\ ${ }^{3}$ Department of Physics, Kumaraguru College of Technology, Coimbatore-641049, TN, India \\ *E-mail: kalapriyaa@gmail.com
}

\begin{abstract}
Cyclic Voltammetric experiments were carried out for the five different classes of dyes to understand the redox behavior (anodic oxidation / cathodic reduction). The redox property of dyes in relation to the dyeability was studied. The dyes selected were of anionic in nature. In the electrochemical method, the fabric was embedded on the anode and potential was applied for coloration purpose. The dyeability results revealed that the depth of shade was independent of the fabric substrate. The color strength $(\mathrm{K} / \mathrm{S})$ was measured by Computer color matching machine and the results were compared between the samples colored by both conventional and embedded systems. The uptake of dye onto the fabric increased with increase in applied potential.
\end{abstract}

Keywords: Cotton, Silk, Polyester, Dyeing, Conventional, Electrochemical

@ RASĀYAN. All rights reserved

\section{INTRODUCTION}

The electrochemical method of dying seems to be of great interest both from economic and ecological points of view in the present day context of eco-friendliness. The conductive fabrics with metal fibers drawn into yarns ${ }^{1}$, or conducting polymer coated fabrics are very much important in the application of smart textiles ${ }^{2,3}$. As the research and commercial interest in the field of smart fabrics in growing day by day, the coloration of these fabrics is also significant ${ }^{4,5}$. The alkaline $\mathrm{pH}$ and the conventional dyeing auxiliaries can negatively impact on the conductivity of fabric ${ }^{6}$. Fabric can be made colored by depositing a layer of ordinary synthetic dyes on the surface of the fabric. Kaynak et al had reported in-situ dyeing and polymerization of pyrrole on wool fabric, where conductivity was very much compromised for color. The dye molecules are supposed to be adsorbed on the surface of the fabric by electrochemical attraction ${ }^{7}$. The objective of this study is to experiment and to compare the dyeability between the conventional and electrochemical coloration on cotton with direct, vat and reactive dyes, silk with acid dye and polyester with disperse dye. This study has been attempted to carry out coloration without external heating, but with electrical potential application only.

\section{EXPERIMENTAL}

Cotton, Silk and Polyester fabrics were purchased from the local market. All chemicals used were of AR grade from Merck. CHI-620A electrochemical unit was used for analyzing the voltammetric redox behavior of synthetic dyes. Cotton fabric was designed, scoured and bleached. Silk and polyester fabrics were weighed and treated with dil. $\mathrm{HCl}$ for 30 minutes in order to remove the impurities and finishes if any. Cotton fabric was dyed with Reactive Blue 4 dye (RB 4), Direct Red 7 dye (DR 7) and Vat Yellow 2 dye (VY2). Silk was dyed with Acid Yellow 17 dye (AY 17) and the polyester fabric was dyed with Disperse Orange 3 dye (DIO 3). The stock solutions of dyes were prepared at 1\% concentration. The dye uptake was measured using Computer Colour Matching (CCM) instrument. 
Conventional dyeing experiment was carried out in an open dye bath at a material to liquor ratio (MLR) of 1:30 following conventional procedures ${ }^{8}$. In the electrochemical method of coloration, the fabric was placed on the anode and a potential of $2 \mathrm{~V}$ was applied using a DC power supply unit. Graphite was used as electrodes. Coloration was carried out for 1 hour. The recipe condition adopted in the conventional dyeing method was also adopted in the electrochemical method of coloration, except the application of heat. No separate heating was done to raise the temperature of the dye bath as the electrodes got heat by the application of the potential itself. The colored fabric was taken out, washed well with water and color strength $(\mathrm{K} / \mathrm{S})$ was measured.

\section{RESULTS AND DISCUSSION}

The cyclic voltammograms obtained for the dyes have revealed that all dyes were electroactive in nature and shown electro-oxidation as well as electro-reduction peaks. Electro-oxidation reactions were more favorable than electro-reduction (Table 1). The voltammetric peak obtained at a particular potential was due to the electron transfer. Lower the peak potential, lesser the energy required to account for the redox reaction.

Table-1: Cyclic voltammetric redox potential data of dyes

\begin{tabular}{c|c|c|c|c|c}
\hline Dye & $\begin{array}{c}\text { Molecular } \\
\text { Weight }\end{array}$ & \multicolumn{2}{|c|}{ Anodic oxidation peak(s) } & \multicolumn{2}{c}{ Cathodic reduction peak(s) } \\
\cline { 3 - 6 } & $\begin{array}{c}\text { Appearance of } \\
\text { first peak in the } \\
\text {-ve potential } \\
\text { range (V) }\end{array}$ & $\begin{array}{c}\text { Appearance of } \\
\text { first peak in the } \\
\text { +ve potential } \\
\text { range (V) }\end{array}$ & $\begin{array}{c}\text { Appearance of first } \\
\text { peak in the +ve } \\
\text { potential (V) }\end{array}$ & $\begin{array}{c}\text { Appearance of first } \\
\text { peak in the -ve } \\
\text { potential (V) }\end{array}$ & -0.583 \\
\hline RB 4 & 637 & -0.483 & 0.787 & -- & -0.529 \\
\hline DR 7 & 697 & -- & 0.293 & -- & -0.739 \\
\hline VY 2 & 479 & -- & 1.006 & -- & -0.084 \\
\hline AY 17 & 551 & -- & 0.041 & -- & -0.755 \\
\hline DIO 3 & 242 & -- & 0.161 & -- & \\
\hline
\end{tabular}

Electrochemical method of dyeing embedded at anode with applied potential of $2 \mathrm{~V}$

In the electrochemical method of coloration at specified conditions with the cotton fabric embedded at the anode, the maximum K/S value was obtained with Direct Red 7. Acid dye produced better coloration than others in the embedded system. The coloration of polyester with Disperse Orange 3 dye has resulted in a moderate K/S value of 1.95 (Table 2). Higher values of K/S obtained in this embedded system could be due to the favored anodic electronic transfer and hence lower energy requirement was inferred from the voltammetric redox analysis of dyes.

Albert Roessler et $\mathrm{al}^{9}$., investigated the application of direct electrochemical reduction of indigo by spectrophotometric and voltammetric experiments. The reaction mechanism and the kinetics show the possibility of the new route for the production of water-soluble indigo, which offers environmental benefits.

Table-2: Dyeing of cotton, silk, and polyester embedded at anode

\begin{tabular}{c|c|c|c|c|c|c|c}
\hline \multicolumn{7}{c}{ Color analysis (LabCH) and color strength (K/S) values of dyed fabrics } \\
\hline \multirow{3}{*}{ Cotton } & Dye & $\mathrm{L}^{*}$ & $\mathrm{a}^{*}$ & $\mathrm{~b}^{*}$ & $\mathrm{C}^{*}$ & $\mathrm{H}$ & $\mathrm{K} / \mathrm{S}$ \\
\cline { 2 - 8 } & $\mathrm{RB} \mathrm{4}$ & 77.55 & -1.60 & 2.56 & 3.02 & 122.02 & 0.74 \\
\cline { 2 - 8 } & DR 7 & 43.76 & 40.99 & -0.68 & 41.00 & 359.05 & 6.27 \\
\cline { 2 - 8 } & VY 2 & 81.35 & 0.04 & 8.15 & 7.15 & 89.73 & 0.66 \\
\hline Silk & AY 17 & 72.69 & -6.39 & 49.10 & 49.51 & 97.42 & 11.71 \\
\hline Polyester & DIO 3 & 67.72 & 10.07 & 19.39 & 21.85 & 62.55 & 1.95 \\
\hline
\end{tabular}

From the electrochemical method of coloration results, it is inferred that the dyes that showed a large gap in peak potential (between anodic and cathodic peak) gave better coloration efficiency in the electrochemical embedded at the anode. The application of potential could ionize the dyes effectively and 
hence trapped easily on to the surface of textiles. This could be the reason for improved coloration when compared to the conventional dyeing method.

Ayoub Haj Said et $a l^{10}$, studied the electrochemical reduction of Vat Blue 1 (indigoid dye) in lucid, average and dark shades. The color and washing fastness of the samples indicated that the performances of the dyeing operation were similar to those obtained by the conventional method.

Considering the dye uptake and washing fastness results, an acid dye produced better dyeability but poor washing fastness when compared to other dyes. Vat and reactive dyes showed poor coloration that could be due to the poor electronic interactions. Direct and disperse dyes showed moderate coloration. In order to understand the role of applied potential in the coloration process, the potential was varied as $3 \mathrm{~V}$ and 4 V. An increase in the applied voltage has resulted in decreased coloration for some dyes, which could be due to the possible deformation in the dye structure. The improved coloration could be due to more accumulation of dye anions within the vicinity of the anode. "L", "a" and "b" data represent the lightness or darkness, redness or greenness, and yellowness or blueness respectively. It is inferred that higher the $\mathrm{L}$ value, lower the coloration and lower the $\mathrm{L}$ value, higher the coloration. " $\mathrm{H}$ " is a measure of hue and is represented as an angle ranging from 0 to $360^{\circ}$. LabCH results were obtained for the samples. If "a" and " $\mathrm{b}$ " are both positive, then the hue angle should be between $0^{\circ}$ and $90^{\circ}$. It was found that both a and $\mathrm{b}$ were positive with DIO 3 and VY 2. In all these dyed samples, the hue angle falls between 62.55 and 89.73. If "a" is negative and " $\mathrm{b}$ " is positive, then the hue angle should be between $90^{\circ}$ and $180^{\circ}$. It was found that with AY 17 and RB 4, a is negative and b is positive and the hue angle is between 97.42 and 122.02. If " $a$ " is positive and " $\mathrm{b}$ " is negative, then the hue angle should be between $270^{\circ}$ and $360^{\circ}$. It was found that with DR 7, $a$ is positive and $b$ is negative and the hue angle falls between 359.05.

Table-3: Comparative analysis of K/S values

\begin{tabular}{c|c|c|c|c}
\hline \multirow{2}{*}{ Dye } & \multicolumn{4}{|c}{ K/S values } \\
\cline { 2 - 5 } & \multicolumn{2}{|c}{ Conventional method of dying } & \multicolumn{2}{c}{ Electrochemical Coloration } \\
\cline { 2 - 5 } & before washing & after washing & before washing & after washing \\
\hline RB4 & 0.77 & 0.71 & 0.74 & 0.70 \\
\hline DR7 & 5.21 & 4.21 & 6.27 & 5.34 \\
\hline VY2 & 0.65 & 0.56 & 0.66 & 0.5 \\
\hline AY17 & 9.38 & 8.55 & 11.71 & 8.43 \\
\hline DIO3 & 1.66 & 1.51 & 1.95 & 1.86 \\
\hline
\end{tabular}

From the table 3, it is observed that the dye uptake was increased in the electrochemical method. This suggests that the dye molecule ionize and this ion migrates towards the fabric by the electrostatic attraction. The migration and deposition of the dye depending on the redox potential and the nature of the electric charge of the electrode.

\section{CONCLUSION}

The electro-active synthetic dyes can be dyed electrochemically on cotton, silk, and polyester by applying potential. Electrochemical coloration with fabric embedded on anode produced improved dye uptake on the fabrics when compared to the conventional method.

\section{REFERENCES}

1. A.G.Avila and J.P.Hinestroza, Nature Nanotechnology, 3, 458 (2008).

2. J. K.Tyagi, Ind.Tex.J., 76 (1986).

3. R. V. Gregory, W. C. Kimbrell and H. H. Kuhn, Syn. Met., 28, 823 (1989).

4. K. W. Oh, K. H. Hong and S. H. Kim, J.Appl.Poly.Sci., 74, 2094(1999)

5. N.V. Bhat, D.T. Seshadri and S. Radhakrishnan, Tex. Res. J., 74, 155 (2004). 
RASĀYAN J. Chem.

Vol. 10 | No. 4 |1330-1333 | October - December | 2017

6. M.S. Kim, H.K. Kim, S.W. Byun, S.H. Jeong, Y.K. Hong, J.S. Jood, K.T. Song, J.K. Jim,C.J. Lee and J.Y. Lee, Syn. Met., 126, 233 (2002).

7. A. Kaynak, R.C. Foitzik and F.M.Pfeffer, Mat. Che. Phy., 113, 480 (2009).

8. S.V.Gokhale, R.C.Shah, "Cotton Piece Dyeing", Ahmedabad Textile Industries Research Association, 6 (1995).

9. A. H. Said, W. Miled, N. Ladhari and S. Roudesli, Journal of Applied Sciences., 8, 2456(2008).

10. A. Roessler, D. Crettenand, O. Dossenbach, W. Marte, P. Rys, Electrochimica Acta., 47, 1989-1995 (2002).

[RJC-1923/2017] 